\title{
Spontaneous Pregnancy after Conventional non- Assisted Reproductive Therapy of Male Infertility due to Sever Oligoasthenoteratozoospermia - Case Report
}

\author{
Ahmed KA ${ }^{1 *}$, Bracamonte $\mathbf{M}^{2}$ and Belqees $\mathrm{A}^{3}$ \\ ${ }^{1}$ Department of Basic Medical Science, International Islamic University, Yemen \\ ${ }^{2}$ Department of Physiology, Sana'a University, Yemen \\ ${ }^{3}$ Department of Clinical Oral Biology, Universiti Kebangsaan Malaysia, Yemen
}

Submission: December 15, 2017; Published: February 19, 2018

*Corresponding author: Ahmed Kaid Allow, Department of Basic Medical Science, International Islamic University, Malaysia also Allow IVF center Sana'a Yemen, Tel: +60177772162; Email: aka@iium.ed.my

\begin{abstract}
A 34-years-old man was diagnosed with primary infertility of 12 years duration due to severe oligoasthenoteratozoospermia (OATS). His hormonal profile was normal. Patient was treated for 2 months using traditional drugs (conventional non-assisted reproductive therapy). After 2 months, spontaneous pregnancy was diagnosed based on an evidently increased $\beta$-human chorionic gonadotropin ( $\beta$-hCG) level in his wife's blood. The pregnancy was confirmed by transabdominal ultra sonography where a gestational sac with $\sim 7$ weeks viable fetus was observed and documented. In conclusion, severe OATS can be successfully treated by conventional non-ART therapy.
\end{abstract}

Keywords : Oligoasthenoteratozoosperiam; Male infertility; Spontaneous pregnancy; Conventional drugs

Abbreviations : NON-ART: Non-Assisted Reproductive Techniques; IVF: In vitro Fertilization; OATS: Oligoasthenoteratozoospermia

\section{Introduction}

Infertility is a worldwide health problem and it is considered as one of the most common health disorders among young adult couples [1]. According to our previous study, male infertility was found to be responsible for $\sim 1 / 3$ (29.9\%) of infertility cases (1281/2622) and the percentage of OATS was around $7 \%(183 / 2622)$ [2]. Jo and Ja Kang in 2016 reported that in $30-45 \%$ of male infertility cases, the cause of the abnormal semen parameters was hesitant. But Jo \& Ja [3] were reported also treatment of OATS is standardized approach for the dealing with idiopathic male infertility but it remains elusive. On the other hand, traditional treatment of OATS by non-assisted reproductive techniques (non-ART) is still not standardized. Regarding the conventional oral therapy (oral therapy by antibiotics and antioxidant) of male infertility due to OATS, a gap in published reviews was noted in the last decade. Furthermore, the conventional ART therapy is still expensive and usually used as the last option of infertility treatment. In this case report, we successfully treated a patient with male infertility due to severe OATS which we called it oral therapy or conventional nonassisted reproductive therapy (non-ART therapy) for infertility treatment. It is the policy of our In vitro Fertilization (IVF)
Center to give a chance for anti- inflammatory, anti-bacterial and supportive therapies before embarking on ART therapy.

\section{Case Report}

A 34-year-old man was presented to IVF Center on 25/1/2017 with primary infertility of 12 years duration. No history of testicular injury, varicocele, torsion/hydrocele, cancer and chemotherapy was found after thorough questioning. Physical examination revealed normal vital signs with a BMI of $23.5 \mathrm{~kg} /$ $\mathrm{m} 2$, bilaterally palpable vas deferens, and normal masculine habitus with no signs of gross abnormalities. He was married to 32-years-old-lady who was apparently reproductively fertile i.e., all infertility investigations were done and shown to be normal. Verbal consent was taken from the couple prior to sending this case report for publication.

\section{Semen analysis}

The semen analysis was investigated on the first visit (patients already familiar with procedures of infertility centers and from the first visit they are usually ready to collect semen analysis for investigation) to the clinic with sexual abstinence period of 3-5 days. Semen was collected in the outpatient semen- 


\section{Global Journal of Reproductive Medicine}

laboratory in a sterile plastic. In the analysis, the volume was measured using a graded tube and the sperm count was done by the manual slide method. Motility was scored as percentages of:

A. Fast forward progressive,

B. Slow forward progressive,

C. Non-progressive and

D. Immotile spermatozoa in total number of 200 counted spermatozoa in at least five power fields per replicate, according to the WHO manual [4].

Table 1: Treatment Protocol traditional drugs for husband (conventional non-ART).

\begin{tabular}{|c|c|}
\hline Doxycycline 100mg tablet & $1 \times 2$ for 2 weeks \\
\hline Vita Zinc Capsules & $1 \times 3$ for 45 days \\
\hline Speman & $1 \times 2$ for 2 months \\
\hline Dostinex 0.5 tablet & $\begin{array}{c}1 / 5 \text { tablet per week for one } \\
\text { month }\end{array}$ \\
\hline $\begin{array}{c}\text { Human Chorionic Gonadotropin } \\
\text { 5000IU/vial }\end{array}$ & $\begin{array}{c}\text { Intramuscular injection once per } \\
\text { week for 2 months }\end{array}$ \\
\hline $\begin{array}{c}\text { Postmenopausal Gonadotropin } \\
\text { injection, Vials 150IU/vial }\end{array}$ & $\begin{array}{c}\text { Intramuscular injection once per } \\
\text { week for 2 months }\end{array}$ \\
\hline
\end{tabular}

His wife was treated by a two weeks course of doxycycline and vaginal wash. At the same time they were advised to avoid intercourse during the course of treatment and the husband was

Table 3 : Fertility Investigations Before and after non- ART -Treatment. asked to do masturbation and ejaculation at least 1-2 times per week, Table $1 \& 2$.

Table 2 : Treatment Protocol traditional drugs for wife (conventional non-ART).

\begin{tabular}{|c|c|}
\hline Doxycycline 100mg tablet & $1 \mathrm{x}$ 2 for 2 weeks \\
\hline Vaginal wash & $\begin{array}{c}\text { One daily for 10 days during the } \\
\text { antibiotic treatment and starting } \\
\text { from day 7 of menstrual period }\end{array}$ \\
\hline Intercourse and intravaginal & $\begin{array}{c}\text { For husband masturbation and } \\
\text { ejaculation was recommended } \\
\text { to be }\end{array}$ \\
\hline $\begin{array}{c}\text { ejaculation was avoided for 1 } \\
\text { month starting from day-1 of } \\
\text { treatment for both husband and } \\
\text { wife }\end{array}$ & $\begin{array}{c}\text { performed 1-2 times per week } \\
\text { during the first month of } \\
\text { treatment }\end{array}$ \\
\hline
\end{tabular}

\section{Results}

After conventional non-ART treatment of this case, an improvement in the semen volume, sperm count and motility were noted and reported, Table 3. Active grade 1 motile sperms were recorded. On 25th May, 2017, the couple reported a oneweek missed-period. During transabdominal ultrasound, a normal gestational sac of 6-7 weeks with viable fetal pool was noted. Pregnancy was confirmed by positive laboratory result for the presence of 2,798.01IU/mL serum beta human chorionic gonadotropin.

\begin{tabular}{|c|c|c|c|c|}
\hline \multirow{2}{*}{ Male Fertility Parameters } & Reference Range & Upon Presentation & Post-Treatment & \multirow{2}{*}{ Notes } \\
\hline & (4) & $25 / 01 / 2017$ & $29 / 03 / 2017$ & \\
\hline Sperm volume (ml) & $2-5$ & 1.7 & 3 & Improved \\
\hline Sperm count $(106 / \mathrm{ml})$ & $>20$ & 0.2 & 3.6 & Increased x 7 \\
\hline Sperm motility (\%) & $>50 \%$ & Zero & 25 & Increased markedly \\
\hline Sperm abnormal morphology (\%) & $>40 \%$ & $68 \%$ & 32 & Decreased \\
\hline Grade-A of activity (\%) & $15 \%$ & Zero & 5 & Increased markedly \\
\hline Grade-B of activity (\%) & $25 \%$ & Zero & 12 & Increased \\
\hline Grade-C of activity (\%) & $35 \%$ & Zero & 30 & Increased \\
\hline Grade-D of activity (\%) & $25 \%$ & $100 \%$ & 53 & Decreased \\
\hline FSH mIU/mL & $1.24-15.6$ & 9.16 & 8.4 & Normal \\
\hline $\mathrm{LH} \mathrm{mIU/mL}$ & $1.42-7.8$ & 7.35 & 5.9 & Normal \\
\hline Testosterone ng/mL & $3-11$ & 3.16 & 8.3 & Increased \\
\hline Prolactin ng/mL & $2-17$ & 14.48 & 9.17 & Decreased \\
\hline
\end{tabular}

\section{Discussion}

Absent or markedly decreased sperm count/motility or both can cause male infertility and is an indicator for an assisted reproductive technique $[5,6]$. However, as in this case, the policy of our IVF center for management of male infertility is to give a chance for classical or conventional non-ART treatment before the couple is enrolled for any assisted reproductive technology (conventional-ART). However, it should be noted that severe oligoasthenoteratospermia is the most difficult to treat among all causes of male infertility and is the cause of approximately $7 \%$ of infertility cases.

The purpose of antibiotic use in this case was to treat any possible infection by fastidious bacteria (which usually reported "no growth" during semen culture test) that may have caused the increased number of white blood cells in the semen analysis in spite of the negative bacterial growth in the semen culture. Allow, et al. [1] had reported that male infertility accounts for a high percentage (40-50\%) of total infertility and that male 
seminal fluid infections and sperm agglutination due to antisperm antibodies account for $17.73 \%$ and $29.90 \%$ respectively of male infertility factor [1].

The role of antioxidants in the management was important to improve the sperm parameters both qualitatively and quantitatively. In a study published by Ashok in 2017, it was reported that antioxidants such as glutathione, vitamins $\mathrm{E}$ and C, carnitines, coenzyme-Q10, N-acetylcysteine, selenium, zinc, folic acid, and lycopene have shown to reduce OS-induced sperm damage [7]. In our case, we believe that all the sperm parameters were improved, at least partially, by the antioxidant treatment.

The role of gonadotropins in this case was also in improving the sperm count, motility and viability. In an observational study of 166 infertile male partners of couples undergoing in-vitro fertilization, it was shown that FSH treatment improves sperm DNA fragmentation, which in turn leads to increased pregnancy rates in infertile males undergoing in-vitro fertilization [8].

\section{Conclusion}

The husband (case) became a father after a mild improvement in his sperm quality tests. We recommend at the end of this case report to extend the study to cover more cases, and if proved beneficial to recommend it as worthwhile effort to try for male infertile-patients with asthenospermia before turning to ARTtherapy.

\section{References}

1. Ahmed KA, Sadek SMA, Bracamonte M, Belqees A (2016) Distribution of Infertility Factors among Infertile Couples in Yemen Abstract. J Clin Dev Biol 1(3): 1-4.

2. Allow A, Abdulmogny S, Bracamonte M, Al-Ani K, Fakhrildin M, et al. (2016) The Relationship between Duration of Infertility and Intrauterine Insemination: A Multi-Centers Study. J Clin Dev Biol 1(3): 1-7.

3. Jo J, Kang MJ (2016) Successful Treatment of Oligoasthenozoospermia Using Traditional Korean Medicine Resulting in Spontaneous Pregnancy: Two Case Reports. Explore (NY) 12(2): 136-138.

4. WHO (2010) World Health Organization. WHO Laboratory Manual for the Examination of Human Semen and Sperm-Cervical Mucus Interaction $\left(5^{\text {th }}\right.$ end) Cambridge Univ Press, Geneva, Switzerland.

5. Allow A, Sadeek A, Bracamonte M (2017) Sperm agglutination, sperm shaky head movement and sperm-cervical interaction tests could be enough for diagnosis of immunological infertility 3(1): 1-6.

6. Katz P, Showstack J, Smith JF, Nachtigall RD, Millstein SG, et al. (2011) Costs of infertility treatment: Results from an 18-month prospective cohort study. Fertil Steril 95(3):915-921.

7. Majzoub A, Agarwal A (2017) Antioxidant therapy in idiopathic oligoasthenoteratozoospermia. Indian J Urol 33(3): 207-214.

8. Garolla A, Ghezzi M, Cosci I, Sartini B, Bottacin A, et al. (2017) FSH treatment in infertile males candidate to assisted reproduction improved sperm DNA fragmentation and pregnancy rate. Endocrine 56(2): 416-425.

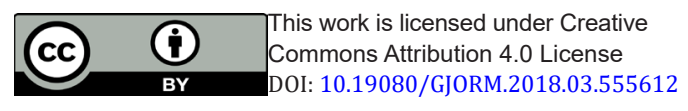

Your next submission with Juniper Publishers
will reach you the below assets
- Quality Editorial service
- Swift Peer Review
- Reprints availability
- E-prints Service
- Manuscript Podcast for convenient understanding
- Global attainment for your research
- Manuscript accessibility in different formats
( Pdf, E-pub, Full Text, Audio)
- Unceasing customer service
Track the below URL for one-step submission
https://juniperpublishers.com/online-submission.php

